\title{
Attitudes and behaviour of general practitioners and their prescribing costs: a national cross sectional survey
}

\author{
C Watkins, I Harvey, P Carthy, L Moore, E Robinson, R Brawn
}

Qual Saf Health Care 2003;12:29-34

\begin{abstract}
Background: General practitioner (GP) prescribing accounts for about 10\% of NHS expenditure. GPs at the top of the range have annual prescribing costs that are almost twice as much as those at the bottom of the range. This variation cannot be accounted for purely in terms of differences in underlying need for health care.

Objectives: To describe the relationship between GPs' prescribing costs and their attitudes towards prescribing decisions and prescribing information sources, and to identify potentially modifiable attitudinal and behavioural factors associated with high cost prescribing.

Design: A postal questionnaire was designed on the basis of hypotheses developed from a literature search and an earlier qualitative survey. This questionnaire was sent to a national sample of GPs with equal numbers of practices in the upper, middle, and lowest quintile of prescribing costs.

Setting: GP practices in England.

Participants: 1714 GPs in NHS practice.

Outcome measures: GPs' self-reported practices, attitudes and personal characteristics.

Results: There was a $64 \%$ response rate. Responders were more likely to be from larger practices, in less deprived areas, and with lower prescribing costs than were non-responders. Multivariable analysis showed that GPs with high prescribing costs were significantly more likely to work in dispensing practices, in practices with low income populations, in single handed practices, and in practices without a GP trainer. They were also significantly more likely to see drug company representatives more frequently, to prescribe newly available drugs more freely, to prescribe more readily to patients who expect a prescription, to report high levels of frustration from lack of time in the consultation, to find unsatisfactory those consultations which ended in advice only, and to express dissatisfaction with their review methods for repeat prescribing. They were significantly less likely to find useful criticism of prescribing habits by colleagues, and to check the BNF rather than other sources when uncertain about an aspect of drug treatment. Conclusions: While they cannot be held to have a causal relationship, the pattern of attitudes towards prescribing of GPs in the highest quintile of prescribing costs provide the basis for developing an educational intervention which may be an acceptable method of modifying the attitudes of GPs and consequently reducing their prescribing costs.
\end{abstract}

See end of article for authors' affiliations

Correspondence to: Dr C Watkins, Backwell and Nailsea Medical Group, Backwell, Bristol BS48 3HA, UK;

chris.watkins@bristol.ac.uk

G eneral practitioner (GP) prescribing accounts for over $£ 5$ thousand million per year, or $10 \%$ of NHS expenditure. ${ }^{1}$ Variation in prescribing costs between GPs is well documented ${ }^{2}$ and has been a concern since the start of the NHS. The average annual prescribing cost per patient is expressed as a prescribing unit (the NIC/ASTRO ${ }^{3}$ ), which corrects for the age, sex, and temporary resident composition of GPs' lists for the 100 health authorities in England. In 1997-8 it ranged from $£ 27$ to $£ 15$. This variation cannot be accounted for purely in terms of differences in underlying need for health care. Indeed, prescribing decisions in general practice are often underpinned by a rationale which may not depend upon recognised pharmacological effects. ${ }^{45}$

Many factors have been identified which have an important relationship with GP prescribing rates and costs. There are those fixed factors for which there is no potential for modification by a change in doctor behaviour-for example, age and sex of $\mathrm{GP}^{6}{ }^{67}$ age and sex of the practice population, ${ }^{89}$ socioeconomic deprivation of the practice area, ${ }^{10}{ }^{11}$ and fund holding status $^{12}$ in the recent past. There are also factors where it is plausible that a change in doctor behaviour or practice organisation will result in modification of prescribing rates and costs. These include knowledge of drugs and drug costs and sources of information, ${ }^{10}{ }^{13-15}$ level of postgraduate medical education, ${ }^{16}$ social and logistic factors such as role perception of GPs and time pressures, ${ }^{817}$ number of GPs in the practice, ${ }^{8}$ and attitudes to generic and branded products. ${ }^{8}{ }^{19} \mathrm{~A}$ number of measures have been adopted in recent years through legislation, local and national policy decision making, and medical audit, in an effort to reduce ineffective or costly prescribing and improve patient care. ${ }^{20}$ These "managerial" interventions - in which behavioural change is encouraged by changes in the regulatory, financial, and organisational environment-constitute a "top down" approach which can evoke resistance from some doctors who fear a loss of clinical freedom and risk to the doctor-patient relationship.

Despite uncertainty about their degree of success, the potential of "bottom up" approaches using educational interventions to influence prescribing decision making in the appraisal and improvement of prescribing practice has been recognised. An understanding of the role of doctors' attitudes and behaviour in determining prescribing frequency and cost is now essential if appropriate and acceptable interventions are to be developed. A postal survey by Avery $e \mathrm{al}^{21}$ of GPs from practices with high and low prescribing costs in the NHS Trent region used a questionnaire derived from suggestions for prescribing cost savings made in the Audit Commission report. ${ }^{2}$ This found that GPs in high cost prescribing practices were significantly less in favour of substitution with comparable but generic drugs. The authors concluded that prescribing advisers may require a different approach for some high cost prescribing practices from the ones conventionally used. 
Table 1 Relationship between practice and personal characteristics of GPs and their prescribing costs

\begin{tabular}{|c|c|c|c|c|}
\hline \multirow[b]{2}{*}{ Variable } & \multicolumn{3}{|c|}{ Prescribing cost category } & \multirow[b]{2}{*}{$\mathrm{p}$ value } \\
\hline & Low & Medium & High & \\
\hline Geometric mean $(95 \% \mathrm{CI})$ LISI score & 9.72 (8.7 to 10.9 ) & 11.57 (10.6 to 12.7$)$ & 16.22 (14.9 to 17.7$)$ & $<0.01$ \\
\hline Sex of GP (\% male) & $65.4 \%$ & $69.4 \%$ & $73.0 \%$ & 0.02 \\
\hline Occupational commitment (\% part time) & $17.9 \%$ & $16.9 \%$ & $17.7 \%$ & 0.95 \\
\hline GP is a GP trainer (\% yes) & $20.2 \%$ & $12.0 \%$ & $9.7 \%$ & 0.01 \\
\hline Mean $(95 \% \mathrm{Cl})$ number of $\mathrm{GPs}$ in practice & 3.94 (3.58 to 4.30$)$ & 4.58 (4.22 to 4.95$)$ & 3.62 (3.32 to 3.97 ) & 0.14 \\
\hline Fundholding status (\% fundholding) & $51.1 \%$ & $53.6 \%$ & $44.6 \%$ & 0.28 \\
\hline Dispensing status (\% dispensing) & $10.4 \%$ & $16.5 \%$ & $13.4 \%$ & 0.47 \\
\hline
\end{tabular}

The aim of this study is to describe the risk factors for high cost prescribing which are potentially modifiable. An understanding of these can form the rational basis for the future development of an empirically based intervention to encourage GPs to modify their prescribing habits.

\section{METHODS}

\section{Study population}

The Prescribing Support Unit of Leeds University analysed the prescribing data provided by the Prescription Pricing Authority for the year 1995-6 for all practices in the 100 English health authorities. Existing PACT and SPA data are reasonably valid at the level of the practice, but are difficult to interpret at the level of the individual practitioner owing to the sharing of prescription pads between GPs. Because of this, costs were calculated for each practice using a standard method: the NIC per ASTRO PU (Net Ingredient Cost per Age, Sex, Temporary Resident, Originated Prescribing Units ${ }^{3}$ ). Practices were ordered into five equal sized groups according to their prescribing costs. A list of a total of 300 randomly selected practices was provided by the Prescribing Support Unit from each of the top, middle and lowest quintiles of prescribing cost. Practices were excluded from this list if they had fewer than 1000 registered patients, or if the Prescribing Support Unit was aware that the practice had been involved in research work at the time of sampling aimed at reducing prescribing costs. Prescriptions written by locums or nurse practitioners were excluded. A further random sample of 200 practices was selected from each of these three groups. Of the 1714 GPs in the final sample, 517 (30\%) were from the lowest cost quintile, $674(40 \%)$ were from the middle cost quintile, and $523(30 \%)$ were from the highest cost quintile of prescribing cost. The Low Income Scheme Index (LISI) is a measure of deprivation based on the proportion of prescribed items that are exempt from the prescription charge under the low income scheme. Using this, a score was calculated for each practice from their prescriptions using methods described elsewhere. ${ }^{22}$ Information about fundholding status, dispensing status, and partnership size of each practice involved in the study was obtained from routinely collected data held by the Prescribing Support Unit.

\section{Data collection}

A questionnaire was designed using hypotheses developed as a result of a search of the literature. The search strategy for the literature review included the following headings to determine factors associated with prescribing variation and cost: "prescribing variation/cost"; "prescribing of the general practitioner"; "GP prescribing behaviour"; "prescribing decision making"; and "decision-support for prescribing" using the following databases: Medline, PsycLIT, EMBASE, BIDS, Sociofile Citation Index, GP/GP, and DHSS from 1960 onwards. Literature was included if it referred to prescribing in general practice and excluded if it concerned prescribing in hospital and private practice. The hypotheses generated by the literature review were refined using an analysis of the views expressed by GPs in an earlier qualitative phase of the project. $^{23}{ }^{24}$ The questions were tested for face and construct validity by a separate group of 17 North Somerset GPs and the refined questions were included in the final questionnaire.

The questionnaire was in four sections. The first section asked GPs to indicate their response to a series of 19 statements about prescribing, in each case using an ordinal five point Likert scale. Three further questions in this section asked about GPs' use of newly licensed drugs, about drug uncertainties (using a nominal multiple category response scale), and about the GPs' frustration over the time available for consultations (using a visual analogue scale). The second section asked the GP for personal and professional details. From this section nine variables were identified which an educational process could not modify. These factors, which are referred to subsequently as "unmodifiable", were GP's age, sex, length of service as a GP, working hours, trainer status, and number of GPs in partnership along with the LISI score, fundholding, and dispensing status. The third section of the questionnaire asked GPs to indicate their agreement with a number of statements about 15 potential methods of receiving prescribing support. The last part of the questionnaire provided the GPs with space for additional comments about their prescribing. Analyses of data collected in these last two sections are not reported in this paper.

The questionnaire was piloted among 50 GPs in the Avon health authority area and, after minor modifications, the postal survey was undertaken in February 1997. There were two further postal distributions of the questionnaire with a reminder letter.

\section{Statistical analysis}

The characteristics and responses of the GPs in each of the three cost categories (high, middle, and low) were compared and $\chi^{2}$ tests for linear trend were undertaken to identify statistically significant univariable relationships. Ordinal logistic regression modelling was used to identify those unmodifiable factors that were significantly associated with prescribing cost. All main effects and two way interactions were tested until a final "base" model was obtained. Multivariable models were then estimated separately for each modifiable factor added in turn to this base model, to assess whether univariate relationships remained significant after adjustment for potential confounding with the unmodifiable factors. The proportional odds assumption of the ordinal logistic models was tested. Since responses from GPs within the same practice cannot be considered independent, $\chi^{2}$ tests and multivariable models were estimated with Stata Statistical Software Release 6.0 (Stata Corporation, 1999) using robust survey estimators that took account of this clustering. Given that valid prescribing cost data were only available at practice level, the models were essentially identifying associations at practice level, but taking proper account of multiple sampling points within practices where two or more GPs responded to the survey. To account for possible non-response 
Table 2 Relationship between the attitudes and reported behaviour of GPs and their prescribing costs

\begin{tabular}{|c|c|c|c|c|}
\hline \multirow[b]{2}{*}{ Variable } & \multicolumn{3}{|l|}{ Prescribing cost category } & \multirow[b]{2}{*}{$\begin{array}{l}\mathrm{p} \\
\text { value }\end{array}$} \\
\hline & Low & Medium & High & \\
\hline \multicolumn{5}{|l|}{ The process of the consultation } \\
\hline $\begin{array}{l}\text { When faced with a patient who expects a prescription (which is not } \\
\text { clinically indicated) my usual response is to ( } \% \text { discuss, but not prescribe) }\end{array}$ & $48.0 \%$ & $42.7 \%$ & $34.3 \%$ & $<0.01$ \\
\hline $\begin{array}{l}\text { When a new drug becomes available what I do most commonly is } \\
\text { (\% use the drug on a few patients and monitor) }\end{array}$ & $9.2 \%$ & $24.3 \%$ & $34.2 \%$ & $<0.01$ \\
\hline $\begin{array}{l}\text { When a new drug becomes available what I do most commonly is } \\
\text { (\% seek published findings of effectiveness) }\end{array}$ & $55.0 \%$ & $44.2 \%$ & $38.8 \%$ & $<0.01$ \\
\hline $\begin{array}{l}\text { I feel that a patient consultation that ends with me giving advice only } \\
\text { is (\% very satisfactory) }\end{array}$ & $38.9 \%$ & $38.3 \%$ & $31.8 \%$ & 0.07 \\
\hline $\begin{array}{l}\text { I find that writing a prescription can be a useful way of ending a } \\
\text { consultation (\% strongly agreeing or agreeing) }\end{array}$ & $49.9 \%$ & $52.9 \%$ & $56.0 \%$ & 0.15 \\
\hline $\begin{array}{l}\text { When I take a history from a patient I elicit their personal health } \\
\text { beliefs about their illness (\% always or usually) }\end{array}$ & $58.6 \%$ & $53.4 \%$ & $60.0 \%$ & 0.74 \\
\hline $\begin{array}{l}\text { Issuing a prescription may act as a cover for my lack of detailed } \\
\text { knowledge (\% strongly disagreeing or disagreeing) }\end{array}$ & $75 \%$ & $66.2 \%$ & $75.8 \%$ & 0.81 \\
\hline $\begin{array}{l}\text { Before prescribing I ask each patient about their "over the counter" } \\
\text { medication (\% always or usually) }\end{array}$ & $52.0 \%$ & $50.9 \%$ & $52.4 \%$ & 0.92 \\
\hline \multicolumn{5}{|l|}{ Attitudes towards criticism of prescribing practices } \\
\hline $\begin{array}{l}\text { I find criticism of my prescribing habits by my colleagues (\% very } \\
\text { useful or useful) }\end{array}$ & $78.5 \%$ & $74.1 \%$ & $70.5 \%$ & 0.04 \\
\hline $\begin{array}{l}\text { There are opportunities for me to compare my prescribing habits with } \\
\text { those of my partners (\% very often or often) }\end{array}$ & $52.8 \%$ & $48.6 \%$ & $47.8 \%$ & 0.29 \\
\hline $\begin{array}{l}\text { I avoid questioning colleagues who appear to be prescribing } \\
\text { inappropriately (\% strongly disagreeing or disagreeing) }\end{array}$ & $51.5 \%$ & $50.2 \%$ & $46.1 \%$ & 0.22 \\
\hline \multicolumn{5}{|l|}{ Sources of information about prescribed and over the counter medication } \\
\hline $\begin{array}{l}\text { My normal practice is to see drug reps in my surgery (\% almost every } \\
\text { day or at least once a week) }\end{array}$ & $28.7 \%$ & $41.8 \%$ & $55.5 \%$ & $<0.01$ \\
\hline $\begin{array}{l}\text { When I receive written promotional material from drug companies I } \\
\text { usually (\% never read it) }\end{array}$ & $29.8 \%$ & $25.0 \%$ & $17.3 \%$ & $<0.01$ \\
\hline I find myself reading drug adverts in journals (\% rarely or never) & $55.3 \%$ & $56.9 \%$ & $49.5 \%$ & 0.17 \\
\hline $\begin{array}{l}\text { When I prescribe, I compare the costs of different drugs which have } \\
\text { the same effect (\%very often or often) }\end{array}$ & $67.8 \%$ & $60.5 \%$ & $61.7 \%$ & 0.13 \\
\hline $\begin{array}{l}\text { When I am uncertain about an aspect of drug treatment, my first } \\
\text { action, before I write the prescription is to: (\% check in BNF) }\end{array}$ & $70.4 \%$ & $68.9 \%$ & $63.7 \%$ & 0.09 \\
\hline $\begin{array}{l}\text { Regular visits from a local retail pharmacist to advise me about } \\
\text { prescribing issues would be helpful (\% strongly agreeing or agreeing) }\end{array}$ & $31.7 \%$ & $40.7 \%$ & $33.1 \%$ & 0.72 \\
\hline $\begin{array}{l}\text { I follow the advice of hospital consultants in deciding which drugs to } \\
\text { use for my patients (\% very often or often) }\end{array}$ & $51.5 \%$ & $56.2 \%$ & $56.6 \%$ & 0.20 \\
\hline $\begin{array}{l}\text { My own prescribing costs are unnecessarily increased by hospital } \\
\text { doctors, who prescribe expensive drugs for my patients (\% strongly } \\
\text { agreeing or agreeing) }\end{array}$ & $65.7 \%$ & $66.0 \%$ & $59.2 \%$ & 0.12 \\
\hline $\begin{array}{l}\text { I am happy that my knowledge of drugs that patients buy over the } \\
\text { counter is up to date (\% strongly agreeing or agreeing) }\end{array}$ & $35.3 \%$ & $38.0 \%$ & $38.0 \%$ & 0.50 \\
\hline $\begin{array}{l}\text { I receive helpful feed back from local retail pharmacists about the } \\
\text { drugs that I am using for patients (\% rarely or never) }\end{array}$ & $69.8 \%$ & $68.6 \%$ & $69.1 \%$ & 0.85 \\
\hline \multicolumn{5}{|l|}{ Feelings of disorganisation } \\
\hline $\begin{array}{l}\text { In my practice, there are adequate mechanisms for reviewing patients' } \\
\text { needs for repeat prescriptions (\% strongly agreeing or agreeing) }\end{array}$ & $80.2 \%$ & $74.8 \%$ & $72.6 \%$ & 0.05 \\
\hline $\begin{array}{l}\text { In what proportion of your consultations do you feel frustrated by } \\
\text { having too little time (mean and } 95 \% \mathrm{Cl} \text { ) }\end{array}$ & $37.8 \%(35.1$ to 40.4$)$ & $41.4 \%$ (38.5 to 44.2$)$ & $43.8 \%(40.9$ to 46.7$)$ & $<0.01$ \\
\hline
\end{tabular}

bias all analyses were repeated on a data set weighted for non-response using weights inversely proportional to response rates within groups defined by prescribing cost quintile and practice size.

\section{RESULTS}

\section{Response rates}

One thousand and ninety seven (64\%) of the 1714 GPs who were mailed the questionnaire responded after three reminders $159 \%$ in the high cost prescribing group, $68 \%$ in the medium cost group and $64 \%$ in the low cost group-a statistically significant variation (Pearson $\chi^{2}=8.93$, $\operatorname{Pr}=0.01$ )) There was a significantly lower response rate among GPs in single handed and smaller practices than those in larger partnerships. The average LISI score ${ }^{22}$ was lower across all three cost groups in responders than non-responders, indicating that those GPs in more economically deprived areas were less likely to respond. In the lowest cost group there was a significantly lower response rate from those in non-training practices than in training practices. There was no significant difference between fundholding practices and nonfundholding practices or between dispensing and nondispensing practices in response rates. The results of the analysis of the data set weighted for non-response and the unweighted data set were similar, so only the results of the unweighted data are presented below.

\section{Practice and GP characteristics}

Table 1 shows the characteristics of the practices and the doctors who work within them, grouped according to their prescribing costs. There are statistically significant linear trends $(p<0.05)$ in the relationship between prescribing costs and the LISI score, sex of GP, and GP trainer status. Fewer high cost prescribing practices were fundholders (45\%) compared with $51 \%$ of low cost prescribing practices and $54 \%$ of medium 
Table 3 Odds ratios (95\% confidence intervals) for being in a higher prescribing cost category obtained from multivariable proportional odds model $(n=967$ samples)

$\left.\begin{array}{lccl}\hline & \begin{array}{c}\text { Odds } \\ \text { ratio }\end{array} & 95 \% \mathrm{Cl} & \text { p value* } \\ \hline \text { log (LISI) } & 3.86 & (2.35 \text { to } 6.34) & <0.01 \\ \text { Sex (female } v \text { male) } & 0.88 & (0.47 \text { to } 1.65) & 0.69 \\ \text { Dispensing status (yes } v \text { no) } & 4.93 & (1.88 \text { to 12.9) } & <0.01 \\ \text { Are you a GP trainer (yes } v \text { no) } & 0.38 & (0.24 \text { to } 0.60) & <0.01 \\ \text { Length of service (GP) } & & & \\ \begin{array}{l}\text { (base }<5 \text { years) } \\ \text { 5-10 years }\end{array} & 0.91 & (0.22 \text { to } 3.78) & \\ \text { 11-20 years } & 0.71 & (0.17 \text { to } 2.89) & 0.09 \\ \text { >20 years } & 4.31 & (0.87 \text { to 21.3) }\end{array}\right\}$

cost prescribing practices, but these differences did not show a significant linear trend.

\section{Univariable analysis}

Table 2 shows the responses of GPs to each of a series of statements about prescribing and also shows the results of the unweighted tests for trend. The statements can be grouped into four categories: the process of consultation; attitudes towards criticism of prescribing practices; sources of information about prescribed and over the counter medication; and feelings of disorganisation. Significantly more GPs in the low cost prescribing group seek published findings of effectiveness before prescribing a newly available drug; find criticism of prescribing habits by their colleagues helpful; never or rarely read promotional material from drug companies; or feel that there are adequate mechanisms for reviewing patient's needs for repeat prescriptions. Significantly fewer GPs in the low cost prescribing group would prescribe when faced with a patient expecting a prescription which was not clinically indicated; would use a newly available drug on a few patients and monitor the results; would see drug representatives in their surgery almost every day or at least once a week; or would feel frustrated because of lack of time in their consultations.

\section{Multivariable analysis}

The final base model is given in table 3 which indicates that six unmodifiable factors were significantly associated with higher prescribing cost-namely, deprivation status (log (LISI)), being a dispensing practice, being a GP trainer, being male, being in a multi-partner practice, and length of service. The model includes two interactions, the first between sex and length of service and the second between length of service and income status of population ( $\log ($ LISI)). The interpretation of odds ratios in ordinal logistic regression models is not straightforward. For example, the full interpretation of the odds ratio for dispensing practice status (4.93) is that, having adjusted for the other unmodifiable factors included in the model, (1) the odds of a dispensing practice being in the highest cost category rather than in the middle or lowest cost category are 4.93 greater than those of a non-dispensing practice, and (2) the odds of a dispensing practice being in the middle or highest cost category rather than in the lowest cost category are also 4.93 greater than those of a non-dispensing practice.

When modifiable variables were added to the base model, eight were statistically significant. The model estimates for these variables are shown in table 4 and indicate the factors that were significantly associated with higher prescribing costs. High cost prescribing GPs were significantly more likely to see drug company representatives more frequently; to prescribe newly available drugs more freely; to prescribe more readily to patients who expect a prescription; to report high levels of frustration from lack of time in the consultation; to find unsatisfactory those consultations which ended in advice only; and to express dissatisfaction with their review methods for repeat prescribing. They were significantly less likely to find useful criticism of prescribing habits by colleagues and to check the BNF rather than other sources when uncertain about an aspect of drug treatment.

Table 4 Odds ratios (OR) with $95 \%$ confidence intervals $(95 \% \mathrm{Cl})$ for being in a higher prescribing cost category for modifiable variables when estimated in a proportional odds model with six unmodifiable factors and significant two way interactions as covariates (only modifiable variables with $p<0.05$ are presented)

\begin{tabular}{|c|c|c|c|}
\hline & Odds ratio $(95 \% \mathrm{Cl})$ & $\begin{array}{l}\text { p value } \\
\text { (adjusted Wald test) }\end{array}$ & $\begin{array}{l}\text { Sample size } \\
\text { for model }\end{array}$ \\
\hline $\begin{array}{l}\text { My normal practice is to see drug reps in my surgery (OR for decreasing frequency) } \\
\text { When a new drug becomes available, what I do most commonly is to: }\end{array}$ & $0.68(0.58$ to 0.80$)$ & $<0.01$ & 965 \\
\hline Seek published findings & - & & 967 \\
\hline Use on a few and monitor & 2.53 (1.82 to 3.49$)$ & $<0.01$ & \\
\hline See what consultants do & $1.04(0.72$ to 1.50$)$ & 0.84 & \\
\hline Other & $1.15(0.79$ to 1.68$)$ & 0.45 & \\
\hline $\begin{array}{l}\text { When faced with a patient who expects a prescription, (which is not clinically indicated) } \\
\text { my usual response is to (OR for decreasing likelihood of prescription) }\end{array}$ & $0.67(0.53$ to 0.85$)$ & $<0.01$ & 931 \\
\hline I find criticism of my prescribing habits by colleagues (OR for decreasing usefulness) & $1.37(1.08$ to 1.74$)$ & $<0.01$ & 956 \\
\hline $\begin{array}{l}\text { In what proportion of your consultations do you feel frustrated by having too little time } \\
\text { (OR for } 10 \text { unit increase in percentage of consultations) }\end{array}$ & 1.08 (1.02 to 1.14$)$ & 0.01 & 960 \\
\hline $\begin{array}{l}\text { I feel that a patient consultation that ends with me giving advice only is (OR for } \\
\text { decreasingly satisfactory) }\end{array}$ & 1.27 (1.05 to 1.54$)$ & 0.02 & 962 \\
\hline $\begin{array}{l}\text { In my practice, there are adequate mechanisms for reviewing patients need for repeat } \\
\text { prescription (OR for decreasing agreement) }\end{array}$ & 1.26 (1.04 to 1.53 ) & 0.02 & 966 \\
\hline \multicolumn{4}{|l|}{$\begin{array}{l}\text { When I am uncertain about an aspect of a drug treatment, my first action, before I write } \\
\text { the prescription is to: }\end{array}$} \\
\hline Check in BNF & - & & 965 \\
\hline Check in MIMS & 1.50 (1.04 to 2.15$)$ & 0.03 & \\
\hline Other & $1.39(0.96$ to 2.02$)$ & 0.08 & \\
\hline
\end{tabular}




\section{DISCUSSION}

The main limitations of this study are those associated with any cross sectional "self-report" questionnaire survey. Firstly, it is not possible to ascribe a causal relationship between prescribing costs and quality and the reported attitudes and behaviours of GPs. Secondly, without independent observational data it is not possible to determine whether the responses to the questionnaire accurately represent the attitudes and behaviour of GPs from whom they are elicited. Another limitation of the study is that existing PACT and SPA data are reasonably valid at the level of the practice but are difficult to interpret at the level of the individual practitioner. The analyses of prescribing costs reported in this paper, while using individual GP data, were estimating relationships at practice level. The strength of reported associations will therefore be conservative since relationships between individual GP's questionnaire responses and their own prescribing costs will have been diluted. The problem of mixing individual exposure variables and aggregate outcome variables in relation to prescribing cost data is discussed in detail by Caudill et al. ${ }^{25}$ The fact that the results in the latter study are similar to our own gives us confidence that our findings are real. The final limitation of the study is that there was a relatively low response rate (59\%) among GPs in the highest quintile of prescribing costs. Because of this, all analyses were undertaken with and without weighting for non-response. The weighted analyses were always very similar to unweighted analyses and are therefore not reported. This provides some reassurance that the model results are representative of all GPs, although we cannot be absolutely confident that this is the case as non-responders may still differ systematically from responders in ways that were not accounted for by the weights calculated.

Behavioural change is particularly difficult to achieve in professional practice. It is therefore recommended that "any proposed change-for example, the implementation of a clinical guideline-would first involve a period of information and diagnostic analysis to inform the development of an appropriate dissemination and implementation strategy". ${ }^{26}$ The study described here and that of Avery et $a l^{21}$ are the first to demonstrate the relationship between the attitudes of GPs and their reported behaviour and prescribing costs. The findings indicate the areas in which educational support might be beneficial and thus contribute to the "information and diagnostic analysis" of the question of how to change the variation in cost of GP prescribing.

The relationship between frequency of seeing drug industry representatives and prescribing costs was striking in this study. In addition, significantly more GPs in the high cost prescribing group reported "prescribing new drugs when they become available on a few patients, and monitoring the results" and also "giving a prescription which is not clinically indicated" than those in the low cost prescribing group. Given the incentive schemes under which pharmaceutical industry representatives work to maximise uptake of new drugs, it would seem plausible that this association is causally related. What is remarkable is that the GPs in the earlier qualitative study ${ }^{23}$ underestimated the influence that seeing drug industry representatives might have on their own prescribing practices or felt that they were in control of the situation. Educational programmes need to inform GPs of the methods used by pharmaceutical representatives to modify their prescribing behaviour and enable them to develop ways to counter them.

Dispensing status, when adjusted for other unmodifiable factors including LISI score, became a statistically significant predictor associated with high prescribing costs. Good knowledge of alternative drugs in such practices, which is likely to lead to reduced prescribing costs, may be outweighed by improved knowledge of new expensive drugs and incentives to

\section{Key messages}

- GPs who generate high prescribing costs are more likely to work in dispensing practices, in practices with low income populations, in single handed practices, and in practices without a GP trainer.

- High cost prescribing GPs are:

- more likely to receive visiting drug company representatives more frequently, to prescribe newly available drugs, to accede to patients who expect a prescription, to feel frustrated from lack of time in the consultation or those that end in advice only, and to express dissatisfaction with their systems for reviewing their repeat prescribing;

- less likely to act upon criticism of their prescribing from colleagues or to check the BNF when uncertain about a prescribing decision.

- The pattern of attitudes of high cost prescribing GPs revealed by this study provides the basis for developing an educational intervention aimed at modifying their attitudes and thus their prescribing behaviour.

increase the profitability of the dispensary through high prescribing rates. Fundholding status was not found to be significantly associated with prescribing costs in any model.

The main aim of this paper, however, was to define those modifiable variables associated with high cost prescribing. There is already evidence of the acceptability and cost effectiveness of a visiting pharmacist to review the way in which repeat prescribing is organised in practices. ${ }^{27}$ Other factors such as the close relationship between drug representatives and some GPs, the patient-doctor relationship, the pressure on consultation time, and the relationship between GPs and their partners and other colleagues may be more difficult to tackle. The high degree of clustering of many of these factors, and the fact that many of them are determined at practice level rather than by individual GPs, suggests that such an intervention should not simply be targeted at individual prescribers but will need to engage multiple partners within each practice to maximise the likely benefit.

Under the new legislation establishing primary care organisations (PCGs and PCTs), ${ }^{28}$ GPs will be responsible for any overspend of their allocated drug budgets. Overspending practices within a PCT will be placed under pressure by their GP colleagues to reduce their prescribing costs. It is important that these GPs receive the support needed to make changes in their prescribing practices. The results of our study provide the basis on which change programmes can be developed rationally on a basis of educational needs.

\section{ACKNOWLEDGEMENTS}

We are grateful to Mr David Roberts and Professor Conrad Harris for their help in advising on study design and for identifying the samples of general practitioners. We are also grateful to Isobel Clark and Sue Williams for their secretarial support, and to the anonymous referees who made helpful comments about the paper. This study was supported by a grant from the Research and Development Directorate of the South and West NHS region of the NHS Executive. The paper was prepared for publication while Dr Watkins was in receipt of a Research Placement Award by the R\&D Directorate of the South and West NHS Executive to enable him to work in the MRC Health Services Research Collaboration, University of Bristol.

\section{Authors' affiliations}

C Watkins, General Practitioner, Backwell and Nailsea Medical Group, Backwell, Bristol BS48 3HA, UK

I Harvey, Professor of Epidemiology and Public Health, School of

Medicine, Health Policy and Practice, University of East Anglia, Norwich NR4 7TJ, UK 
P Carthy, Research Associate, Research and Development Support Unit, Salisbury Health Care NHS Trust, Salisbury District Hospital, Salisbury, Wiltshire SP2 8BJ, UK

L Moore, Senior Research Fellow, Cardiff University School of Social Sciences, Cardiff CF10 3WT, UK

E Robinson, General Practitioner, Bloomsbury Surgery, 1 Handel Street, London WCIN 1PB, UK

R Brawn, Lecturer in Education, The Graduate School of Education, Bristol BS8 1JA, UK

Chris Watkins and lan Harvey were responsible for the conception, design, initiation and overall coordination of the study. Pat Carthy designed and produced the questionnaire and subsequently obtained, analysed, and interpreted the data. Laurence Moore analysed and interpreted the data. Elizabeth Robinson gave advice on the interpretation of GP prescribing costs and factors affecting these costs. Richard Brawn gave advice on the educational aspects of the project. Chris Watkins prepared the manuscript and all investigators contributed to the final version of this report.

$\mathrm{CW}$ and $\mathrm{IH}$ are members of the MRC Health Services Research Collaboration and CW is Consultant in Primary Care R\&D, North Somerset PCT. The Backwell and Nailsea Medical Group receives funding from the NHS Executive. The views expressed in this publication are those of the authors and not necessarily those of the NHS Executive or the MRC HSRC.

\section{REFERENCES}

1 Department of Health. Prescriptions dispensed in the community: statistics for 1989 to 1999. Statistical bulletin 2000/20. London: Department of Health, 2000 (also available at http://www.doh.gov.uk/ public/sb2020.htm).

2 Audit Commission. A prescription for movement towards more rational prescribing in general practice. London: Audit Commission, 1996: 9-12

3 Roberts SJ, Harris CM. Age, sex and temporary resident originated prescribing units (ASTRO PUs): new weightings for analysing prescribing of general practices in England. BM 1993;307:485-8.

4 Schwartz RK, Soumerai SB, Avorn J. Physician motivations for nonscientific drug prescribing. Soc Sci Med 1989;28:577-82.

5 Weiss $M$, Fitzpatrick R. Challenges to medicine: the case of prescribing Sociol Health III 1997; 19:297-327.

6 Howie JG. Clinical judgement and antibiotic use in general practice. BM 1976;2:1061-4

7 Hartley RM, Charlton JR, Harris CM, et al. Patterns of physicians' use of medical resources in ambulatory settings. Am J Public Health 1998;77:565-7.

8 Carrin G. Drug prescribing: a discussion of its variability and (ir) rationality. Health Policy 1987;73-94.
9 Healey A, Yule B, Reid J. Variations in general practice prescribing costs and implications for budget setting. Health Econ 1994;3:47-56.

10 Forster DP, Frost CEB. Use of regression analysis to explain the variation in prescribing rates and costs between family practitioner committees. $\mathrm{Br}$ J Gen Pract 1991;41:67-71.

11 Baker D, Klein R. Explaining outputs of primary health care: population and practice factors. BM 1991;303:225-9.

12 Morton-Jones T, Pringle M. Explaining variations in prescribing costs across England. BM 1993;306:1731-4.

13 Coleman JS, Katz E, Menzel H. Medical innovation. A diffusion study ndianapolis: The Bobbs-Merril Company Inc, 2000.

14 Peay M, Peay E. Differences among practitioners in patterns of preference for information sources in the adoption of new drugs. Soc $\mathrm{Sci}$ Med 1984; 18:1019-25.

15 Ryan M, Yule B, Bond C, et al. Scottish general practitioners' attitudes and knowledge in respect of prescribing costs. $B M V 1990 ; 300: 1316-8$.

16 Becker MH, Stolley P, Lasagna L, et al. Correlates of physicians' prescribing behaviour. Inquiry 1972;9:30-42.

17 Bradley C. Factors which influence the decision whether or not to prescribe: the dilemma facing general practitioners. Br J Gen Pract 1992;42:454-8.

18 Harris CM, Jarman B, Woodman E, et al. Prescribing: a suitable case for yreatment. London: Royal College of General Practitioners, 1984.

19 Van Zwanenberg TD, Grant GB, Gregory DA. Can rational prescribing be assessed? J R Coll Gen Pract 1987;37:308-10.

20 National Prescribing Centre, NHS Executive. GP prescribing support: a resource document for the new NHS. London: NHS Executive, 1998.

21 Avery AJ, Wetzels RV, Rodgers S, et al. Do GPs working in practice with high or low prescribing costs have different views on prescribing cost issues? Br J Gen Pract 2000;50:100-4.

22 Lloyd DCEF, Harris CM, Clucas DW. Low Income Scheme Index: a new deprivation scale based on prescribing in general practice. BM 1995; 310:165-70.

23 Carthy P, Brawn JR, Harvey I, et al. A study of factors associated with cost and variation in prescribing among general practitioners. Fam Pract 2000; 17:36-41.

24 Carthy P. Variation in prescribing in general practice. PhD Thesis, University of Bristol, 2000.

25 Caudill TS, Johnson MS, Rich EC, et al. Physicians, pharmaceutical sales representatives, and the cost of prescribing. Arch Fam Med 1996:5:201-6.

26 NHS Centre for Reviews and Dissemination. Getting evidence into practice. Effective Health Care 1999;5:1-16.

27 Rodgers S, Avery A, Meechan D, et al. Controlled trial of pharmacist intervention in general practice: the effect on prescribing costs. $\mathrm{Br} J \mathrm{Gen}$ Pract 1999;49:717-20

28 NHS Executive. A first class service quality in the new NHS. London: Department of Health, 1998. 